\title{
LATE PULMONARY VALVE REPLACEMENT AFTER REPAIR OF TETRALOGY OF FALLOT
}

Berent Discigil, MD

Joseph A. Dearani, MD

Francisco J. Puga, MD

Hartzell V. Schaff, MD $^{\mathrm{a}}$

Donald J. Hagler, $\mathrm{MD}^{\mathrm{b}}$

Carole A. Warnes, $\mathrm{MD}^{\mathrm{c}}$

Gordon K. Danielson, MD
Background: Pulmonary regurgitation appears to be well tolerated early after repair of tetralogy of Fallot; however, it may result in progressive right ventricular dilatation and dysfunction necessitating eventual valve replacement. Our objective was to review our experience with late pulmonary valve replacement after complete repair of tetralogy of Fallot.

Methods and results: A total of 42 patients (16 female and 26 male) were operated on between July 1, 1974, and January 1, 1998. Mean age was 22 years (range 2-65 years). The mean interval between tetralogy repair and pulmonary valve replacement was 10.8 years (range 1.6 months-33 years). Mean followup was $7.8 \pm 6.0$ years (maximum 23 years). Indications for pulmonary valve replacement included decreased exercise tolerance in $58 \%$, right heart failure in $21 \%$, arrhythmia in $14 \%$, syncope in $10 \%$, and progressive isolated right ventricular dilatation in 7\%. Heterograft prostheses were used in 33 patients and homografts in 9. Five patients underwent isolated pulmonary valve replacement; concomitant procedures performed in 37 patients included tricuspid valve repair/replacement $(n=18)$, residual ventricular septal defect repair $(n=12)$, atrial septal defect closure $(n=4)$, pulmonary artery patch angioplasty $(n=17)$, and right ventricular outflow tract enlargement $(n=13)$. One patient died early (2\%) of multiorgan failure. There were 6 late deaths, 3 of which were cardiac related. Survival was $95.1 \% \pm 3.4 \%$ and $76.4 \% \pm 8.9 \%$ at 5 and 10 years, respectively. Functional class of patients was improved significantly; preoperatively, $76 \%$ of patients were in New York Heart Association class III-IV, and after pulmonary valve replacement, $97 \%$ of surviving patients were in class I-II $(P=.0001)$. Moderate to severe reduction in right ventricular function was noted on preoperative echocardiography in 59\% and on late echocardiography in $18 \%(P=.03)$. Of the 5 patients who had supraventricular arrhythmias before pulmonary valve replacement, 1 had postoperative recurrence and the arrhythmia is controlled with antiarrhythmic therapy; the other 4 are in normal sinus rhythm at late follow-up. Eight patients subsequently underwent pulmonary valve re-replacement without early mortality at a mean interval of $9.0 \pm 4.2$ years (range 3.8-16.8 years). Freedom from pulmonary valve re-replacement was $93.1 \% \pm 4.7 \%$ and $69.8 \% \pm 10.7 \%$ at 5 and 10 years, respectively. The only significant risk factor for re-replacement was young age at the time of the initial pulmonary valve replacement $(P=.023)$.

Conclusion: Late pulmonary valve replacement after tetralogy repair significantly improves right ventricular function, functional class, and atrial arrhythmias, and it can be performed with low mortality. Subsequent re-replacement may be necessary to maintain functional improvement. (J Thorac Cardiovasc Surg 2001;121:344-51)
From the Division of Cardiovascular and Thoracic Surgery, ${ }^{a}$ Section of Pediatric Cardiology, ${ }^{\mathrm{b}}$ Division of Cardiovascular Diseases, ${ }^{\mathrm{c}}$ Mayo Clinic and Mayo Foundation, Rochester, Minn.

Received for publication May 25, 2000; revisions requested July 13, 2000; revisions received Aug 25, 2000; accepted for publication Aug 28, 2000.
Address for reprints: Joseph A. Dearani, MD, Mayo Clinic, 200 First St, SW, Rochester, MN 55905 (E-mail: jdearani@ mayo.edu).

Copyright $\odot 2001$ by The American Association for Thoracic Surgery

$0022-5223 / 2001 \$ 35.00+0 \quad \mathbf{1 2 / 1 / 1 1 1 2 0 9}$

doi:10.1067/mtc.2001.111209 
$\mathrm{R}$ epair of tetralogy of Fallot (TOF) has been performed for more than 4 decades, and a favorable long-term outcome has been documented for most patients. ${ }^{1-4}$ Approximately 5\% of patients require reoperation after repair of TOF. Indications for reoperation have included pulmonary regurgitation or stenosis, residual right ventricular (RV) outflow tract obstruction, conduit degeneration, residual ventricular septal defect, aortic valve regurgitation or stenosis, and tricuspid regurgitation. ${ }^{1,3-8}$ As the number of long-term survivors increases, the late complications of heart failure, arrhythmias, and sudden death have also increased.

Although many patients with severe pulmonary regurgitation may be asymptomatic, a deleterious effect on RV function and exercise capacity has been demonstrated. ${ }^{9}$ This becomes more important when other hemodynamically significant lesions such as distal pulmonary artery stenosis or residual ventricular septal defect are present. In addition, evidence suggests that long-standing pulmonary regurgitation with right heart enlargement may be associated with the development of arrhythmias and sudden death. ${ }^{10-14}$ Previous studies have shown that pulmonary valve replacement (PVR) for symptomatic pulmonary regurgitation improves functional status and RV function. ${ }^{6,15-20}$ The purpose of this review was to examine our late results of PVR after repair of TOF.

\section{Patients and methods}

Patient population. Between July 1, 1974, and January 1, 1998, 42 patients (16 female, 26 male) underwent PVR after repair of TOF at our institution. Demographic data are shown in Table I. Exclusion criteria included patients who had a valved conduit placed from the right ventricle to the pulmonary artery at the time of TOF repair and patients with major associated congenital cardiac malformations such as complete atrioventricular canal with TOF. The majority of patients (76\%) were in New York Heart Association (NYHA) class III or IV preoperatively. Palliative operations that were performed before TOF repair are shown in Table IIA, and operations performed after TOF repair and before PVR are shown in Table IIB. Management of the RV outflow tract obstruction at the time of TOF repair is shown in Table III.

Evaluations of pulmonary and tricuspid regurgitation and RV dysfunction and enlargement were subjectively classified into mild, moderate, moderately severe, and severe. Preoperative echocardiography $(n=36)$ demonstrated moderately severe or severe pulmonary regurgitation in all patients, moderately severe to severe tricuspid regurgitation in $38 \%$, moderately severe to severe reduction in RV function in 59\%, and moderate to severe RV enlargement in $69 \%$ of patients. Preoperative cardiac catheterization was performed in 32 (76\%) patients; hemodynamic data are shown in Table IV. A major indication for operation in all patients was pulmonary regurgitation. Other associated lesions were common and included tricuspid regurgitation, residual ventricular septal defect, and RV outflow tract or pulmonary artery obstruction. Decreased exercise tolerance was present in 24 (58\%) patients, symptomatic right heart failure in 9 (21\%), RV and right atrial dilatation with associated supraventricular arrhythmias in 5 (12\%), progressive RV dilatation without arrhythmias in $3(7 \%)$, and intermittent ventricular tachycardia in $1(2 \%)$. In our practice, we have used the following criteria to help select patients who would benefit from PVR after TOF repair: (1) the presence or progression of symptoms (ie, decreased exercise tolerance and poor functional class), (2) evidence of deteriorating RV function or significant and progressive RV enlargement, (3) the development or progression of atrial and/or ventricular arrhythmias, or (4) the development/progression of tricuspid regurgitation.

Follow-up. Clinical data were collected from the patients' medical records. Each patient (or parent) and/or personal physician was interviewed with a standardized telephone questionnaire.

Statistical analysis. Early (hospital) mortality was defined as death within 30 days of operation or before hospital discharge, whichever was longer. Clinical and demographic variables were expressed as mean and standard deviation. Continuous variables were analyzed with Wilcoxon rank-sum tests. Comparisons of preoperative and postoperative echo measurements and NYHA class were done by means of the sign rank test. Survival and survivorship free of reoperation were estimated by the Kaplan-Meier method. ${ }^{21}$ Survival curves were compared with log-rank tests. ${ }^{22}$ The effect of continuous variables on survival and the relationships of risk factors to survival were evaluated with the Cox proportionalhazards model. ${ }^{23}$

\section{Results}

All patients underwent standard surgical techniques including repeat median sternotomy and cardiopulmonary bypass. PVR and concomitant procedures could be performed without aortic crossclamping in 20 (48\%) patients. Aortic crossclamping was necessary in $22(52 \%)$ patients, and a period of circulatory arrest was required in 3 patients. PVR was performed with a porcine heterograft prosthesis in $25(60 \%)$ patients, a pericardial heterograft prosthesis in $8(19 \%)$, an aortic homograft in $6(14 \%)$, and a pulmonary homograft in 3 (7\%). Isolated PVR was performed in $5(12 \%)$ and PVR with associated procedures was performed in 37 (88\%) (Table V). The mean time interval between index operation and PVR for isolated PVR (9.7 years) versus PVR with a concomitant procedure (10.9 years) was not significantly different $(P=.8)$. The median heterograft pulmonary valve size was $25 \mathrm{~mm}$ (range $17-31 \mathrm{~mm}$ ) and the median homograft valve size was $23 \mathrm{~mm}$ (range 21-26 mm). Intraoperative prebypass peak systolic RV pressure was $61.9 \pm 28 \mathrm{~mm} \mathrm{Hg}$ compared with $49 \pm 11 \mathrm{~mm} \mathrm{Hg}$ after bypass $(P=.624)$. The 
Table I. Demographic data of 42 patients undergoing late PVR after TOF repair

\begin{tabular}{lrr}
\hline & Mean $\pm S D$ & Range \\
\hline TOF repair (patient age) & $11.2 \pm 14.8 \mathrm{y}$ & 2.5 mo-61 y \\
PVR $(\mathrm{n}=42)$ (patient age) & $22 \pm 16.4 \mathrm{y}$ & $1.8 \mathrm{y}-65 \mathrm{y}$ \\
Interval, repair to isolated PVR $(\mathrm{n}=5)$ & $9.7 \pm 11.3 \mathrm{y}$ & $2.1 \mathrm{y}-29.3 \mathrm{y}$ \\
Interval, repair to PVR + other* $(\mathrm{n}=37)$ & $11.0 \pm 9.4 \mathrm{y}$ & $1.3 \mathrm{mo}-33.1 \mathrm{y}$ \\
Re-PVR $(\mathrm{n}=8)$ (patient age) & $16.7 \pm 8.1 \mathrm{y}$ & $5.5 \mathrm{mo}-29.6 \mathrm{y}$ \\
Interval, PVR to re-PVR & $9.0 \pm 4.2 \mathrm{y}$ & $3.8 \mathrm{y}-16.8 \mathrm{y}$ \\
\hline
\end{tabular}

$P V R$, Pulmonary valve replacement; TOF, tetralogy of Fallot.

$*$ Other $=$ concomitant procedure .

Table IIA. Palliative procedures performed in 28 patients before TOF repair*

\begin{tabular}{lrc}
\hline Procedure & No. & $\%$ \\
\hline Blalock-Taussig & 16 & 38 \\
$\quad$ Classic & 6 & 14 \\
$\quad$ Modified & 10 & 24 \\
Waterston & 5 & 12 \\
Potts & 3 & 7 \\
Other $\dagger$ & 4 & 9.5 \\
\hline
\end{tabular}

TOF, Tetralogy of Fallot.

*Some patients had more than one palliative procedure.

$\nmid$ Pulmonary valvotomy $(\mathrm{n}=1)$, pulmonary valvectomy $(\mathrm{n}=1)$, Brock infundibulectomy $(\mathrm{n}=1)$, and closed right ventricular outflow tract reconstruction $(\mathrm{n}=1)$

Table IIB. Procedures performed in 5 patients after TOF repair and before late $P V R$

\begin{tabular}{lcc}
\hline Procedure & No. & $\%$ \\
\hline VSD patch leak repair (Qp:Qs > 1.5) & 3 & 7 \\
PA aneurysm plication & 1 & 2 \\
Coronary artery bypass grafting & 1 & 2
\end{tabular}

$P A$, Pulmonary artery; $P V R$, pulmonary valve replacement; $Q p: Q s$, pulmonary/systemic flow ratio; VSD, ventricular septal defect.

Table III. Management of the RV outflow tract obstruction at the time of TOF repair*

\begin{tabular}{lrr}
\hline Procedure & No. & $\%$ \\
\hline Infundibular muscle resection $\dagger$ & 38 & 90 \\
Transannular patch $\dagger$ & 29 & 69 \\
Pulmonary valvotomy, no patch & 9 & 21 \\
Pulmonary valvectomy, no patch & 2 & 5
\end{tabular}

$R V$, Right ventricular; $T O F$, tetralogy of Fallot.

*Some patients had more than one outflow tract procedure.

$\dagger$ With associated valvotomy or valvectomy.

peak systolic right ventricular/left ventricular (RV/LV) pressure ratio before and after bypass was $0.58 \pm 0.17$ and $0.46 \pm 0.12$, respectively $(P=.01)$.

Early mortality occurred in $1(2 \%)$ patient. This patient underwent repair of TOF at 5 years of age, and
Table IV. Cardiac catheterization data in 32 (76\%) patients before late PVR after TOF repair*

\begin{tabular}{lc}
\hline Variable & Mean $\pm S D$ \\
\hline PA systolic pressure (mm Hg) & $53 \pm 20$ \\
PA diastolic pressure (mm Hg) & $9.9 \pm 6.9$ \\
Peak RV systolic pressure (mm Hg) & $62.6 \pm 19.8$ \\
Peak systolic RV/LV ratio & $0.56 \pm 0.18$
\end{tabular}

$L V$, Left ventricular; $P A$, pulmonary artery; $P V R$, pulmonary valve replacement; $R V$, right ventricular; $T O F$, tetralogy of Fallot.

*Twelve patients had leakage of a ventricular septal defect patch with a pulmonary/systemic flow ratio of 1.5 or less.

Table V. Associated procedures performed in patients undergoing PVR after TOF repair

\begin{tabular}{lcc}
\hline & No. of patients & $\%$ \\
\hline Associated procedures* & 37 & 88 \\
PA patch angioplasty & 17 & 40 \\
Tricuspid valve repair & 16 & 38 \\
RVOT patch enlargement & 13 & 31 \\
VSD patch leak repair & 12 & 29 \\
ASD closure & 4 & 10 \\
Repair RVOT aneurysm & 3 & 7 \\
Distal PA dilatation & 3 & 7 \\
Tricuspid valve replacement & 2 & 5 \\
CABG & 2 & 5 \\
Right-sided maze procedure & 1 & 2 \\
Aortic valve replacement & 1 & 2 \\
Potts anastomosis closure & 1 & 2 \\
\hline
\end{tabular}

$A S D$, Atrial septal defect; $C A B G$, coronary artery bypass grafting; $P A$, pulmonary artery; $P V R$, pulmonary valve replacement; $R V O T$, right ventricular outflow tract; TOF, tetralogy of Fallot; VSD, ventricular septal defect.

*Some patients had more than one associated procedure.

PVR was performed at 19 years of age for poor exercise tolerance, severe RV dilatation and dysfunction, and right-sided heart failure with ascites and peripheral edema. In addition, he had severe tricuspid regurgitation and stenoses of the superior vena cava and right pulmonary vein. The LV ejection fraction was $30 \%$ to $35 \%$. The operative procedure included PVR (heterograft $23 \mathrm{~mm}$ ), tricuspid valve replacement (heterograft 


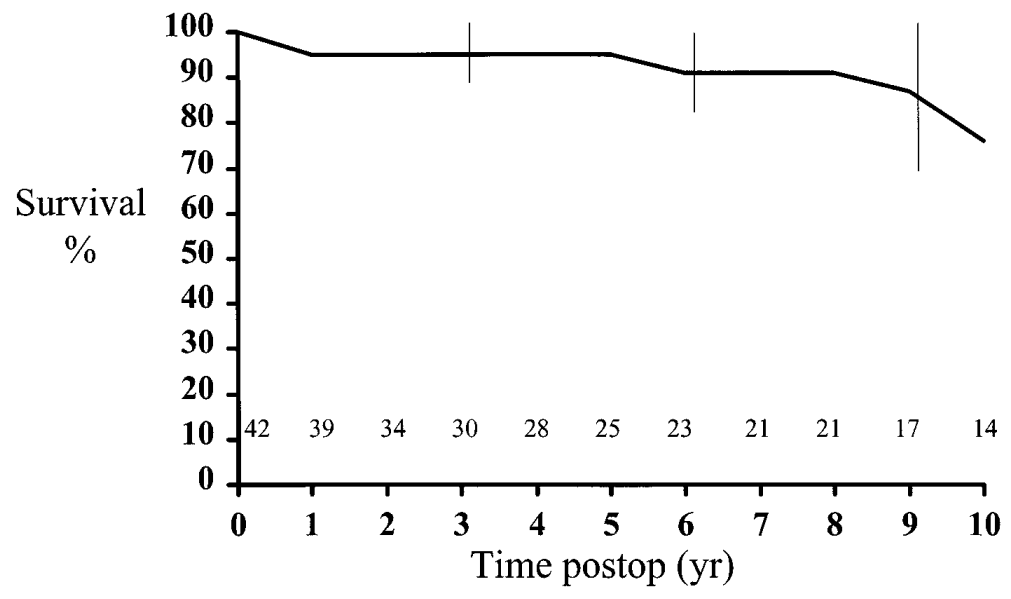

Fig 1. Overall survival for all patients $(n=42)$ undergoing PVR after TOF repair. Expected survival for an ageand sex-matched population is also shown.

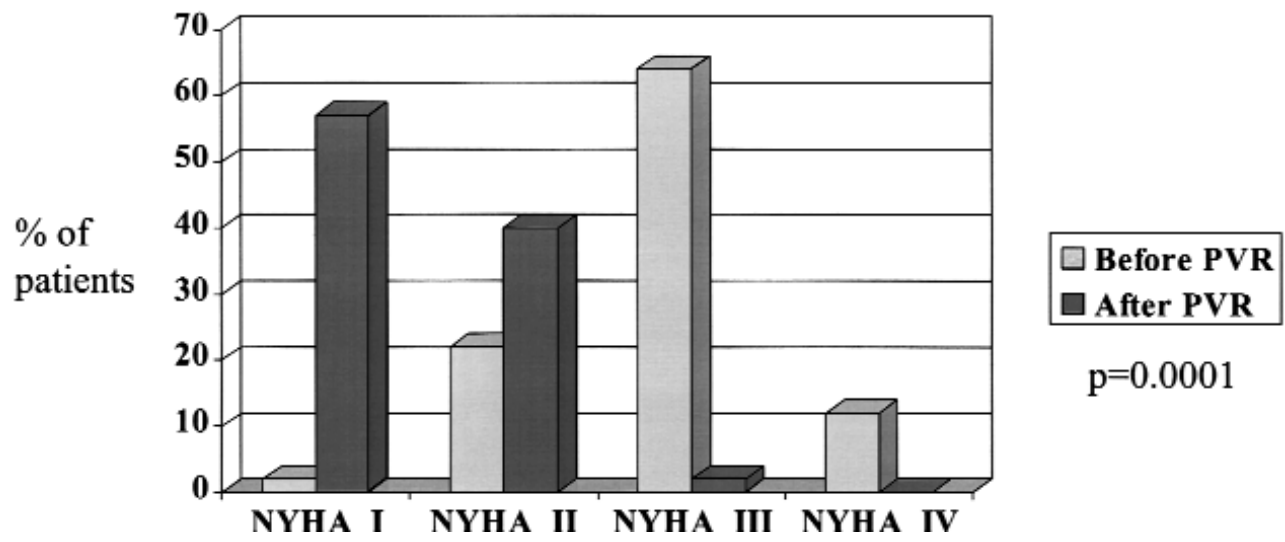

Fig 2. NYHA functional class before and at last follow-up in patients undergoing PVR after TOF repair.

$29 \mathrm{~mm}$ ), and patch enlargement of the superior vena cava and right-sided pulmonary veins. The postbypass RV/LV pressure ratio was 0.7 and the gradient across the pulmonary prosthesis was $5 \mathrm{~mm} \mathrm{Hg}$. His postoperative course was complicated by multisystem organ failure, and he died 40 days after the operation.

Morbidity included prolonged ventilatory support ( $>48$ hours) in 7 (17\%) patients, sternal wound infection in $2(5 \%)$, and stroke, lower extremity compartment syndrome, exploration for bleeding, and partial gastrectomy for gastrointestinal bleeding in 1 (2\%) patient each. The mean length of hospital stay was 14.5 days.

Follow-up. Follow-up was complete in all patients and ranged up to 22.9 years. Total follow-up was 329.5 patient-years and the mean follow-up was $7.8 \pm 6.0$ years. There were 6 late deaths, 3 of which were known to be cardiac related. Overall survival for all patients (n $=42$ ) was $95.1 \% \pm 3.4 \%$ and $76.4 \% \pm 8.9 \%$ at 5 and 10 years, respectively (Fig 1). The first late cardiac death occurred in a 65-year-old woman who died of chronic biventricular heart failure 8.2 years after PVR. She had undergone PVR 7 weeks after complete repair of TOF for poor exercise tolerance, progressive RV dilatation, and right-sided heart failure. The second death occurred in a 13-year-old boy with TOF and absent pulmonary valve syndrome who died suddenly while playing soccer 5 years after PVR, presumably of an arrhythmia. At autopsy the right ventricle showed marked dilatation. He had no known arrhythmias 


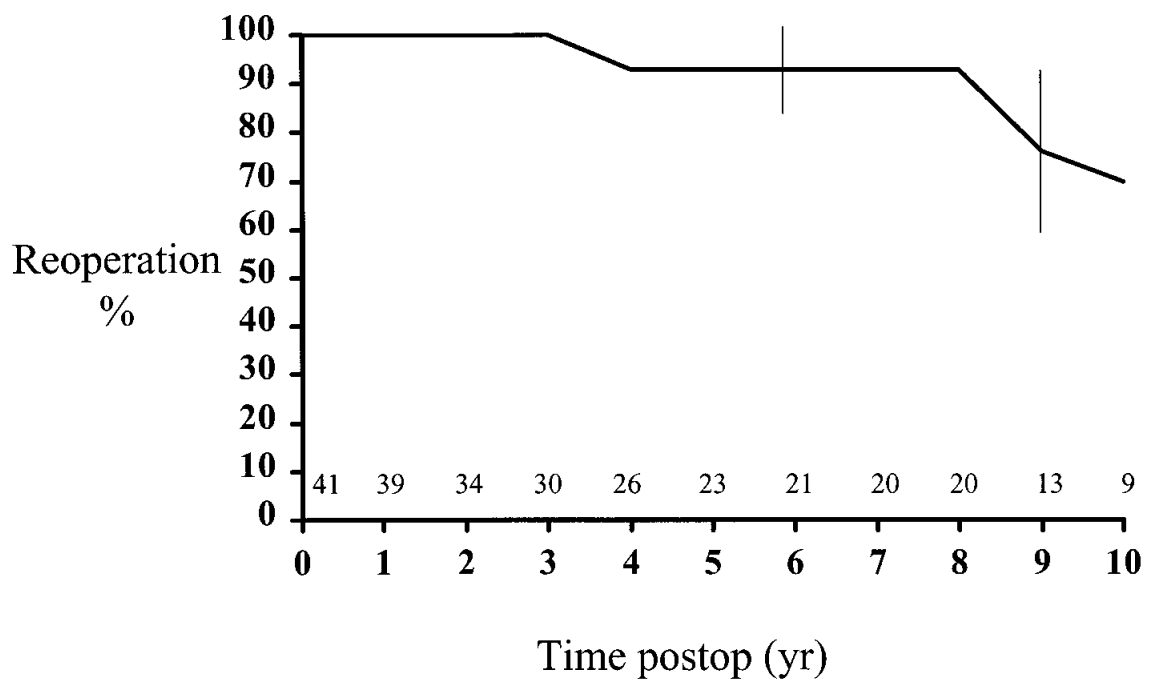

Fig 3. Freedom from re-PVR in patients who underwent PVR after TOF repair.

before PVR. The third cardiac death occurred in a 27year-old man with a history of ventricular tachycardia before PVR; he died suddenly 8 months after PVR, presumably of an arrhythmia. Marked RV dilatation was found at autopsy. Because the number of late cardiac deaths was small $(n=3)$, univariate analysis could not demonstrate any significant risk factors for cardiacrelated late mortality. Specifically, preoperative NYHA class, age at the time of PVR, the time interval between TOF repair and PVR, intraoperative peak RV pressure, and intraoperative peak RV/LV pressure ratio were not found to be significant risk factors.

Late echocardiography performed at a mean of 8.2 years after the operation (range 8 months-17 years) demonstrated persistent moderate to severe reduction in RV function in $18 \%$ (vs $59 \%$ preoperatively, $P=$ .03 ), and moderate to severe RV enlargement was noted in $44 \%$ (vs $69 \%$ preoperatively, $P=.06$ ). Mild or no residual tricuspid regurgitation was noted in $90 \%$ of patients. There were no residual atrial or ventricular septal defects.

Among the 5 patients who had supraventricular arrhythmias before PVR (including 1 patient with chronic atrial fibrillation who underwent a right-sided maze procedure), 1 patient had a recurrence of arrhythmias 5 years after PVR. This patient ultimately underwent placement of a permanent pacemaker for sinus node dysfunction. She has been maintained in a paced atrioventricular rhythm receiving amiodarone therapy without recurrence of atrial fibrillation. The other 4 are in normal sinus rhythm without antiarrhythmic agents. One of the 5 patients also had frequent premature ven- tricular beats and syncope before the operation; there has been no reported recurrent syncopal event or significant ventricular ectopy after PVR. Severe RV and right atrial dilatation were present preoperatively in all 5 patients who had supraventricular arrhythmias; at late follow-up, only mild to moderate RV dilatation was present. The patient with chronic atrial fibrillation who underwent a right-sided maze procedure is in sinus rhythm at follow-up. NYHA functional class of patients was improved significantly; preoperatively, $76 \%$ of patients were in NYHA class III-IV, and after PVR, 97\% of surviving patients were in NYHA class III $(P=.0001)$ (Fig 2).

Eight patients have subsequently required re-replacement of the pulmonary valve (re-PVR) at a mean time of $9.0 \pm 4.2$ years (range 3.8-16.8 years) after PVR. There was no early mortality. All 8 patients who underwent re-PVR had had a heterograft prosthesis (6 porcine, 2 pericardial) placed at the time of PVR; the mean age at PVR was 7.7 years (range 1.8-18 years). Prostheses used at the time of re-PVR were pulmonary homograft in 4 , aortic homograft in 2 , and porcine heterograft in 2. Freedom from re-PVR was $93.1 \% \pm 4.7 \%$ and $69.8 \% \pm 10.7 \%$ at 5 and 10 years, respectively (Fig $3)$. Preoperative NYHA class III or IV was not a risk factor for re-PVR $(P=.69)$. The only significant risk factor for re-PVR by univariate analysis was young age at the time of PVR $(P=.023)$.

\section{Discussion}

Numerous studies have demonstrated very good long-term survival and good quality of life in the 
majority of patients after repair of TOF. ${ }^{1,2}$ As the number of long-term survivors after repair of TOF increases, so does the number of late complications. Pulmonary regurgitation after repair of TOF is common, especially in patients who require a transannular patch reconstruction at the time of repair. Although pulmonary regurgitation can be well tolerated for many years, it eventually results in progressive RV dilatation, dysfunction, and symptoms, necessitating PVR. Severe pulmonary regurgitation in the presence of associated lesions such as residual RV outflow tract obstruction or residual ventricular septal defect is usually less well tolerated and may necessitate reoperation even earlier. Despite the causes for reoperation, the early mortality has been low and the late survival and functional results have generally been very good. ${ }^{6-8,15-17,19,20,24}$ The late results of patients undergoing PVR after repair of TOF in this review are consistent with those of previous reports.

Isolated PVR was performed in a minority of patients (only $12 \%$ ) in the present study. The expected longer time interval between TOF repair and PVR for patients with isolated pulmonary regurgitation as compared with those with pulmonary regurgitation plus additional hemodynamic problems was not present in this series. This may be due to the small number of patients undergoing isolated PVR or the relatively minor degrees of the associated defects. These included mild to moderate RV outflow tract or distal pulmonary artery obstruction (preoperative peak RV/LV pressure ratio was $0.58 \pm 0.17$ ) or small residual ventricular septal defect (pulmonary/systemic flow rate $<1.5$ ).

Determining the appropriate time for PVR in patients with significant pulmonary regurgitation can be difficult. Ideally, all important anatomic lesions should be treated early to avoid deterioration of RV function and development of associated problems. However, all bioprostheses have a limited life expectancy, and one would like to avoid PVR until it is clearly indicated. The only early death in this series occurred in a patient who had a delayed referral for operation. On preoperative evaluation, he had very limited exercise tolerance, severe RV dilatation, severe tricuspid regurgitation, right-sided heart failure with ascites and peripheral edema, and severe depression of both RV and LV function. We believe surgery should be considered long before such advanced clinical deterioration has occurred. In our practice, current indications for PVR after TOF repair have included the presence and progression of symptoms (decreased exercise tolerance and poor functional class), the development/progression of arrhythmias (especially ventricular arrhyth- mias), evidence of deteriorating RV function, and development and progression of tricuspid regurgitation. In addition to PVR, it has been our policy to repair concomitantly all additional anatomic lesions such as atrial or ventricular septal defects, tricuspid regurgitation, and surgically accessible proximal and distal pulmonary artery stenoses, even if they are mild, to provide the best opportunity for recovery of RV function. Although RV size decreased in most patients, this reduction did not reach statistical significance $(P=$ .06), despite the finding of significant improvement in RV function $(P=.03)$. Since the majority of patients had only mild or no residual tricuspid regurgitation (90\%) at late follow-up, persistent RV dilatation is more likely due to chronic underlying changes in the myocardium and thus would be less likely to regress after PVR. Since the problems related to late arrhythmias can be important and may be related to RV dilatation, our practice over the years has been to advise PVR earlier with the hope that irreversible anatomic and pathologic changes in the myocardium would be avoided.

Previous studies have demonstrated correlations between supraventricular or ventricular arrhythmias due to right-sided heart enlargement after TOF repair and the occurrence of sudden death. ${ }^{10-14}$ Six patients in this review had arrhythmias before PVR: 5 supraventricular and 1 ventricular. Of the 3 known late cardiac related deaths, 2 were due to presumed arrhythmias but only 1 of the patients was known to have had an arrhythmia (paroxysmal ventricular tachycardia) before PVR. One of the 5 patients who had a preoperative supraventricular arrhythmia was in chronic atrial fibrillation; a right-sided maze procedure ${ }^{25}$ was performed in conjunction with PVR, and sinus rhythm was present after the operation. Although 3 patients who had other types of supraventricular tachycardia were also in normal sinus rhythm postoperatively as a result of correction of their pulmonary regurgitation and other anatomic defects, this favorable outcome cannot be expected in all patients. Accordingly, for patients having documented preoperative supraventricular arrhythmias, we prefer to perform concomitant appropriate antiarrhythmia procedures (right-sided maze, cryoablation, division of accessory conduction pathways) at the time of PVR. In addition, a right reduction atrioplasty is also performed if right atrial enlargement is marked.

Two patients died suddenly during follow-up; one was known to have paroxysmal ventricular tachycardia preoperatively. Postmortem examination of the hearts showed severe right atrial and RV dilatation in both. 
Persisting RV dilatation and dysfunction are known to be substrates for ventricular arrhythmias and sudden death. ${ }^{10-14}$ Prevention of progressive RV dilatation and dysfunction is a major reason for advising PVR, even in the absence of symptoms. For patients with known paroxysmal ventricular tachycardia, complex ventricular premature beats, or a history of syncope or sustained palpitations, we usually perform a preoperative electrophysiologic study. The primary reason for preoperative study is to identify and locate the mechanism of any inducible ventricular tachycardia to direct a surgical approach for tachycardia ablation. Some ventricular arrhythmias will not reappear after PVR and repair of all other hemodynamic lesions, especially if a successful surgical ablation can be performed. However, if ventricular arrhythmias were present postoperatively, especially in the presence of RV dilatation, an electrophysiologic study would be repeated and strong consideration given to prophylactic implantation of an automatic internal cardioverter-defibrillator.

Although the mean interval from TOF repair to PVR was 9 years in this review, 1 patient who required PVR soon after TOF repair requires special comment. She had undergone an uneventful TOF repair with a transannular patch at the age of 56 years. However, she returned 6 weeks later with exercise intolerance and a dilated right ventricle. A small residual ventricular septal defect was also present. She underwent PVR with closure of the ventricular septal defect (one stitch) and subsequently improved considerably. Although pulmonary regurgitation appears to be well tolerated in children after TOF repair, we and others ${ }^{26}$ have observed that adults may tolerate pulmonary regurgitation less well. Accordingly, we currently perform PVR in nearly all adult patients undergoing primary repair of TOF.

The only risk for re-PVR in the 8 patients who required reoperation was young age at the time of PVR. Although no significant difference in valve durability was detected between types of prostheses used (heterograft vs homograft) in this small number of patients, we presently do not favor cryopreserved homografts in older children and adults because of their disappointing late results. ${ }^{27}$

Our current preference is to place the largest porcine bioprosthesis possible (in adults a size 27 or $29 \mathrm{~mm}$ ) at or just below (apical to) the pulmonary anulus. Room for the prosthesis is created by a pericardial patch that roofs and enlarges the RV outflow tract, pulmonary anulus, and proximal main pulmonary artery. ${ }^{6,18,24}$ In our experience, the durability of this type of reconstruction is much better than that for cryopreserved homografts. ${ }^{18}$ We have performed this technique to reconstruct the right ventricle-pulmonary artery connection since 1983 in more than 80 adult patients with congenital heart disease and have had no known reoperations for prosthetic valve failure. The overall conduct of repeat sternotomy for PVR or revision of the right ventricle-pulmonary artery connection consists of aortic and single right atrial cannulation with mild to moderate hypothermia with no aortic occlusion in the absence of residual septal defects. Bicaval cannulation is performed when additional intracardiac repair is required. Aortic occlusion is used for additional procedures that would require cardioplegic arrest (eg, repair of an atrial or ventricular septal defect or aortic valve replacement). The decision to expose the femoral vessels before the repeat sternotomy is determined by the operating surgeon. The presence of a severely dilated right atrium and right ventricle, in addition to the absence of a radiolucent line on lateral chest $\mathrm{x}$-ray film between the posterior sternum and anterior heart, is sometimes helpful in determining potentially high-risk reopenings. A previously placed right ventricle-pulmonary artery conduit that is directly posterior to the sternum would also suggest potential problems with sternal re-entry. Despite these findings, exposure of the femoral vessels before repeat sternotomy is performed in only a small percentage of patients. We prefer to use the largest stented heterograft prosthesis possible and to augment the roof of the RV outflow tract with pericardium (usually glutaraldehyde-preserved bovine pericardium) to maximize prosthetic valve size. In our practice, the use of the homograft (aortic or pulmonary) to reconstruct the right ventricle is reserved for infants, small children, and patients undergoing the Ross procedure. Although the use of mechanical prostheses in the pulmonary position has been described in the literature, ${ }^{28,29}$ we have generally avoided their use because of the low right-sided pressures, potential thrombosis problems, and the need for long-term anticoagulation. Intraoperative RV and pulmonary arterial pressures are measured before and after PVR, and intraoperative transesophageal echocardiogram is used routinely.

Limitations of this study include the lack of postoperative catheterization data to quantitate improvement in hemodynamics and lack of exercise testing before and after surgery to assess improvement in cardiopulmonary function. However, significant subjective improvement in functional class was observed in almost all patients, as judged by the patients as well as their physicians. Others have been able to show significant objective improvement in cardiorespiratory parameters after PVR. ${ }^{15,17,30}$ Reduction of heart size on 
chest radiographs late after PVR was dramatic in some patients, but a more definitive assessment of improvement would have been provided by serial measurements of cardiothoracic ratios. Severity of RV dysfunction and enlargement was assessed subjectively and noted retrospectively from clinical echocardiography and cardiac catheterization reports. More recent techniques for echocardiographic assessment of ventricular function would have provided more precise data for preoperative and postoperative comparisons.

In summary, late PVR after TOF repair significantly improves RV function, functional class, and atrial arrhythmias. PVR can be performed with low mortality. Subsequent re-PVR may be necessary to maintain functional improvement.

We gratefully acknowledge the assistance of Duane M. Ilstrup, MS, and Betty J. Anderson, RN, in the statistical analysis, and Terrie L. Fischer for her secretarial support.

\section{REFERENCES}

1. Murphy JG, Gersh BJ, Mair DD, et al. Long-term outcome in patients undergoing surgical repair of tetralogy of Fallot. N Engl J Med 1993;329:593-9.

2. Katz NM, Blackstone EH, Kirklin JW, et al. Late survival and symptoms after repair of tetralogy of Fallot. Circulation 1982;65:403-10.

3. Lillehei CW, Warden HE, DeWall RA, et al. The first open-heart corrections of tetralogy of Fallot: a 26-31 year follow-up of 106 patients. Ann Surg 1986;204:490-502.

4. Fuster V, McGoon DC, Kennedy MA, et al. Long-term evaluation (12 to 22 years) of open-heart surgery for tetralogy of Fallot. Am J Cardiol 1980;46:635-42.

5. Zhao HX, Miller DC, Reitz BA, et al. Surgical repair of tetralogy of Fallot. J Thorac Cardiovasc Surg 1985;89:204-20.

6. Finck SJ, Puga FJ, Danielson GK. Pulmonary valve insertion during reoperation for tetralogy of Fallot. Ann Thorac Surg 1988;45:610-3.

7. Oechslin EN, Harrison DA, Harris L, et al. Reoperation in adults with repair of tetralogy of Fallot: indications and outcomes. J Thorac Cardiovasc Surg 1999;118:245-51.

8. Uretzky G, Puga FJ, Danielson GK, et al. Reoperation after correction of tetralogy of Fallot. Circulation 1981;66(Suppl):I-2028.

9. Bove EL, Byrum CJ, Thomas FD, et al. The influence of pulmonary insufficiency on ventricular function following repair of tetralogy of Fallot. J Thorac Cardiovasc Surg 1983;85:691-6.

10. Quattlebaum TB, Varghese J, Neill CA, et al. Sudden death among postoperative patients with tetralogy of Fallot. Circulation 1976;54:289-93.

11. Burns RJ, Liu PP, Druck MN, et al. Analysis of adults with and without complex ventricular arrhythmias after repair of tetralogy of Fallot. J Am Coll Cardiol 1984;4:226-33.

12. Gatzoulis MA, Till JA, Somerville J, et al. Mechanoelectrical interaction in tetralogy of Fallot: QRS prolongation relates to right ventricular size and predicts malignant ventricular arrhythmias and sudden death. Circulation 1995;92:231-7.

13. Dietl CA, Cazzaniga ME, Dubner SJ, et al. Life-threatening arrhythmias and RV dysfunction after surgical repair of tetralogy of Fallot: comparison between transventricular and transatrial approaches. Circulation 1994;90(Suppl):II-7-12.

14. Downer E, Harris K, Kimber S. Ventricular tachycardia after surgical repair of tetralogy of Fallot: results of intraoperative mapping studies. J Am Coll Cardiol 1992;20:648-55.

15. Bove EL, Kavey REW, Byrum CJ, et al. Improved right ventricular function following late pulmonary valve replacement for residual pulmonary insufficiency or stenosis. J Thorac Cardiovasc Surg 1985;90:50-5.

16. Saher RM, Foster E, Farina M, et al. Right heart reconstruction following repair of tetralogy of Fallot. Ann Thorac Surg 1983;35:421-6.

17. Ilbawi MN, Idriss FS, DeLeon SY, et al. Long-term results of porcine valve insertion of pulmonary regurgitation following repair of tetralogy of Fallot. Ann Thorac Surg 1986;41:478-82.

18. Cerfolio RJ, Danielson GK, Warnes CA, et al. Results of an autologous tissue reconstruction for replacement of obstructed extracardiac conduits. J Thorac Cardiovasc Surg 1995;110: 1359-68.

19. Misbach GA, Turley K, Ebert PA. Pulmonary valve replacement for regurgitation after repair of tetralogy of Fallot. Ann Thorac Surg 1983;26:684-91.

20 Yemets IM, Williams WG, Webb GD, et al. Pulmonary valve replacement after repair of tetralogy of Fallot. Ann Thorac Surg 1997;64:526-30

21. Kaplan EL, Meier P. Nonparametric estimation from incomplete observations. J Am Stat Assoc 1958;53:457-81.

22. Peto R, Peto J. Asymptotically efficient rank invariant procedures (with discussion). J R Stat Soc 1972;135(Series A):185-207.

23. Cox DR. Regression models and life-tables (with discussion). J R Stat Soc 1972;34(Series B):187-220.

24. Laks H, Hellenbrandt WE, Kleinman CS, et al. Patch reconstruction of the right ventricular outflow tract with pulmonary valve insertion. Circulation 1981;64(Suppl):II-154-61.

25. Theodoro DA, Danielson GK, Porter CJ, Warnes CA. Right-sided maze procedure for right atrial arrhythmias in congenital disease. Ann Thorac Surg 1998;65:149-54.

26. Yankah AC, Sievers PE, Lange D, et al. Surgical repair of tetralogy of Fallot in adolescents and adults. Thorac Cardiovasc Surg 1982;30:69-74.

27. Bando K, Danielson GK, Schaff HV, et al. Outcome of pulmonary and aortic homografts for right ventricular outflow tract reconstruction. J Thorac Cardiovasc Surg 1995;109:509-18.

28. Rosti L, Murzi B, Colli AM, Festa P, Redalli S, Frigola A. Pulmonary valve replacement: A role for mechanical prostheses? (letter). Ann Thorac Surg 1998;65:888-900.

29. Rosti L, Murzi B, Colli AM, et al. Mechanical valves in the pulmonary position: a reappraisal. J Thorac Cardiovasc Surg 1998;115:1074-9.

30. Warner KG, Anderson JE, Fulton DR, et al. Restoration of the pulmonary valve reduces right ventricular volume overload after previous repair of tetralogy of Fallot. Circulation 1993;88 (Suppl):II-189-97. 